\title{
Insights into the pre-eruptive spatiotemporal magma dynamics of the last eruption of Kizimen (Kamchatka, Russia)
}

\author{
LEA OSTORERO ${ }^{1}$, HÉLÈNE BALCONE-BOISSARD ${ }^{2}$, \\ GEORGES BOUDON $^{1}$, ALEXANDER BELOUSOV ${ }^{3}$,

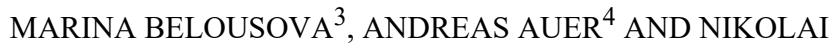 \\ SHAPIRO $^{5}$ \\ ${ }^{1}$ Université de Paris, Institut de physique du globe de Paris, \\ CNRS, F-75005 \\ ${ }^{2}$ Institut des Sciences de la Terre de Paris (ISTeP), UMR 7193, \\ CNRS-Sorbonne Université \\ ${ }^{3}$ Institute of Volcanology and Seismology \\ ${ }^{4}$ Department of Geoscience, Shimane University, 1060 \\ Nishikawatsu \\ ${ }^{5}$ Institut des Sciences de la Terre (ISTERRE), Université \\ Grenoble Alpes, CNRS \\ Presenting Author: ostorero@ipgp.fr
}

Unraveling the spatiotemporal dynamics of the mush-bearing magma plumbing system leading to volcanic eruptions can provide information on the mitigation of volcanic hazards, all the more if a correlation between these dynamics and monitoring signals can be established. On Kizimen volcano, in Kamchatka (Russia), the pre-eruptive magma dynamics in the reservoirs prior to its first historical magmatic eruption in 2010-2013 are deciphered through orthopyroxenes and magnetites. A 3-week fieldtrip has been done in August 2019 on Kizimen volcano to collect representative samples: dacites and silica-rich andesites (called "hybrid"). On orthopyroxenes, the combination of a Crystal System Analysis approach with intracrystalline Fe-Mg interdiffusion modeling allows to specify the timescales of disrupting events prior to eruption. On magnetites, Ti diffusion modeling is used to estimate the timescales of magma ascent in the conduit during the eruption. On orthopyroxenes, young timescales, mostly around 1-2 years prior to the eruption, are found: they mainly correspond to a change between two magmatic environments, towards a hotter one for hybrid samples and a colder one for the dacites. These timescales can be correlated with the onset of a seismic crisis 1 year and a half before the eruption. Some older timescales are found that could be related to a magmatic intrusion several decades before the eruption. Timescales of the order of days to months are found in magnetites. As this eruption has been well monitored by the Institute of Seismology and Volcanology of Petropavlovsk in Kamchatka, ongoing precise treatment of seismological record will lead to a better correlation of petrological results to monitoring data. 